\title{
Accuracy of breeding values in small genotyped populations using different sources of external information-A simulation study
}

\author{
S. Andonov, ${ }^{* 1}$ D. A. L. Lourenco,† B. O. Fragomeni, $†$ Y. Masuda,† I. Pocrnic, $†$ S. Tsuruta, $†$ and I. Misztal† \\ ${ }^{*}$ Faculty of Agricultural Sciences and Food, University of Ss. Cyril and Methodius, PO Box 297, 1000 Skopje, Macedonia \\ †Department of Animal and Dairy Science, University of Georgia, Athens 30602
}

\begin{abstract}
Genetically linked small and large dairy cattle populations were simulated to test the effect of different sources of information from foreign populations on the accuracy of predicting breeding values for young animals in a small population. A large dairy cattle population $\left(\mathrm{P}_{\mathrm{L}}\right)$ with $>20$ generations was simulated, and a small subpopulation $\left(\mathrm{P}_{\mathrm{S}}\right)$ with 3 generations was formed as a related population, including phenotypes and genomic information. Predicted breeding values for young animals in the small population were calculated using BLUP and single-step genomic BLUP (ssGBLUP) in 4 different scenarios: (S1) 3,166 phenotypes, 22,855 pedigree animals, and 1,000 to 6,000 genotypes for $\mathrm{P}_{\mathrm{S}}$; (S2) $\mathrm{S} 1$ plus genomic estimated breeding value (GEBV) for 4,475 sires from $\mathrm{P}_{\mathrm{L}}$ as external information; (S3) S1 plus 221,580 phenotypes, 402,829 pedigree animals, and 53,558 genotypes for $\mathrm{P}_{\mathrm{L}}$; and (S4) single nucleotide polymorphism (SNP) effects calculated based on $\mathrm{P}_{\mathrm{L}}$ data. The ability to predict true breeding value was assessed in the youngest third of the genotyped animals in the small population. When data only from the small population were used and 1,000 animals were genotyped, the accuracy of GEBV was only 1 point greater than the estimated breeding value accuracy (0.32 vs. 0.31). Adding external GEBV for sires from $\mathrm{P}_{\mathrm{L}}$ did not considerably increase accuracy (0.33 vs. 0.32 in $\mathrm{S} 1$ ). Combining phenotypes, pedigree, and genotypes for $\mathrm{P}_{\mathrm{S}}$ and $\mathrm{P}_{\mathrm{L}}$ was beneficial for predicting accuracy of GEBV in the small population, and the prediction accuracy of GEBV in this scenario was 0.38 compared with 0.31 from estimated breeding values. When SNP effects from $P_{L}$ were used to predict GEBV for young genotyped animals from $\mathrm{P}_{\mathrm{S}}$, accuracy was greatest (0.56). With 6,000 genotyped animal in $\mathrm{P}_{\mathrm{S}}$, accuracy was greatest (0.61) with the combined popu-
\end{abstract}

Received April 19, 2016.

Accepted September 12, 2016.

${ }^{1}$ Corresponding author: sreten_andonov@yahoo.com or sandonov@ zf.ukim.edu.mk lations. In a small population with few genotypes, the highest accuracy of evaluation may be obtained by using SNP effects derived from a related large population. Key words: dairy cattle, genomic breeding value, prediction accuracy, small population

\section{INTRODUCTION}

National dairy cattle breeding programs of 30 countries have become comparable because of the use of the same superior animals and participation in the multitrait, across-country evaluation (Schaeffer, 1994) of the Interbull Centre (Uppsala, Sweden). In countries with fairly small Holstein populations, population maintenance and progress rely on the continuous import of genetic material (pregnant heifers, semen, and embryos). Despite importation, such countries still have an interest in national breeding programs. Whereas reliabilities from evaluations with small populations are low, they can benefit from using evaluations from large reference populations, which have more traits recorded and higher reliabilities (Wiggans et al., 2011).

Genomic selection can provide increased reliability of predictions, increased genetic gain, and reduced generation interval (Schaeffer, 2006). Use of genomic selection for livestock has become widespread because of the availability of cost-effective genotyping. Adding genomic to pedigree and phenotypic information leads to increased accuracy of genomic EBV (GEBV), particularly when the training population has a large set of genomic and phenotypic data (Hayes et al., 2009; VanRaden et al., 2009; Lund et al., 2011). In addition, the genetic merit of young sires can be predicted with high accuracy without progeny performance. As a consequence, breeding organizations have begun to exchange genomic information for sires in addition to their EBV (Cromie et al., 2010). Members of the EuroGenomics consortium have already benefited from exchange of genomic data in GEBV estimation of sires used across countries and in genetic predictions for young animals without progeny records (Patry, 2015). In such evaluations, all available sources of information 
(e.g., relationship to common ancestors, phenotypes, and genotypes) are included and require robust and reliable methodology.

Information from large populations can be incorporated in several ways. First, EBV or GEBV from external data can be used as priors for BLUP, either in nongenomic (Legarra et al., 2007) or genomic context (Přibyl et al., 2014; Vandenplas et al., 2014; VanRaden et al., 2014). Second, if complete data sharing agreements are available, data from multiple countries can be combined. Use of all information including female genotypes is simplified by the use of single-step genomic BLUP (ssGBLUP; Aguilar et al., 2010; Legarra et al., 2014). It benefits from the inclusion of all relatives of nongenotyped and genotyped animals and their performance without losing information; an additional benefit is the use of the same models as in traditional evaluations. Initially, ssGBLUP could not account for $>150,000$ genotyped animals, but that limitation has been overcome through additional algorithms developed by Misztal et al. (2014). The so-called algorithm for proven and young was recently used in the evaluation of Holstein data with more than 7 million phenotypes and almost 570,000 genotypes (Masuda et al., 2016). Third, GEBV for genotyped animals in a small population can be computed by using SNP effects derived from a large population (Council on Dairy Cattle Breeding, 2016). Whereas GEBV from small populations require blending of SNP-derived values with parent average, that blending is no longer needed when SNP effects are derived from a large number of genotypes (Lourenco et al., 2015). In the extreme, SNP effects can be backsolved from genotypes and GEBV.

The different socio-economic and environmental conditions in different countries with small Holstein populations result in constraints in designing a breeding program that is genetically effective and economically reasonable. Even though genotyping cost has been decreasing, it is still an unaffordable and questionable investment for countries with small populations with limited economic power. The objective of this study was to investigate, by simulation, the accuracy of evaluation on a small population with different approaches for incorporating information from a large related population.

\section{MATERIALS AND METHODS}

\section{Simulation}

To mimic a Holstein population, data were generated with QMSim simulation software (Sargolzaei and Schenkel, 2009); 2 linked populations were simulated in 5 replicates. To start, a large population $\left(\mathbf{P}_{\mathbf{L}}\right)$ of 400,000 animals over 20 generations was simulated, and then a small population $\left(\mathbf{P}_{\mathbf{S}}\right)$ of 6,000 animals over only 3 generations and partially related to $\mathrm{P}_{\mathrm{L}}$ was simulated. To produce a realistic level of linkage disequilibrium, 800 generations of a historical population were generated with initially 3,000 animals, increasing to 40,000 at generation 500 , and then decreasing to 30,000 by the last generation; one-tenth of animals were sires. The $\mathrm{P}_{\mathrm{L}}$ was founded by 2,000 sires and 20,000 dams from the historical population; single records were generated for dams, and heritability was set to 0.3 . The replacement rate for sires and dams was 90 and 30\%, respectively; the selection criterion was based on high EBV. Only 1 calf was allowed for each calving. For $\mathrm{P}_{\mathrm{S}}$, the first generation was founded by 150 sires and 2,000 dams from generation 18 of $\mathrm{P}_{\mathrm{L}}$; for the second generation, an additional 100 sires were used from generation 19 of $\mathrm{P}_{\mathrm{L}}$ to ensure strong genetic ties between $\mathrm{P}_{\mathrm{L}}$ and $\mathrm{P}_{\mathrm{S}}$. The structure of $\mathrm{P}_{\mathrm{S}}$ was similar to $\mathrm{P}_{\mathrm{L}}$ except for less intensive culling of sires (50\%) and random selection criterion.

Genotypes were simulated for 45,000 biallelic SNP markers distributed along 29 chromosomes with a total length of 2,319 cM, which mimicked the bovine genome without sex chromosomes. A total of 450 biallelic and randomly distributed QTL affected the trait, with effects sampled from a normal distribution. Genomic information was generated for generations 14 through 20 of $\mathrm{P}_{\mathrm{L}}$ and all 3 generations of $\mathrm{P}_{\mathrm{S}}$. Because of the considerable amount of genomic information generated for $\mathrm{P}_{\mathrm{L}}$, only genotypes for sires and dams with more than 2 offspring were kept, thus reducing the computational effort in analysis that included $\mathrm{P}_{\mathrm{L}}$ genotypes. Mean linkage disequilibrium ranged from 0.3 to 0.4 for both populations among replicates.

\section{Scenarios}

Four different scenarios were defined according to the source of information used for the evaluation (Table 1). The first scenario (S1) mimicked a local evaluation where, on average, 3,166 phenotypes, 22,885 pedigree animals, and 1,000 genotypes were available only for animals in $\mathrm{P}_{S}$; in this scenario, we indicate the output GEBV as $\mathrm{P}_{\mathrm{S}}$ GEBV. The second scenario (S2) used all the information for S1 plus external GEBV from 4,475 $\mathrm{P}_{\mathrm{L}}$ sires of animals in $\mathrm{P}_{\mathrm{S}}$, which was used as prior information for the local evaluation (Legarra et al., 2007); in this scenario, we indicate the output GEBV as $\mathrm{P}_{\mathrm{S}}+$ GEBV. The next scenario (S3) mimicked an ideal situation where phenotypes, pedigree, and genotypes from a large population are available to be included in the 
Table 1. Sources of local and shared information used for all 4 genomic scenarios and respective outcomes from the evaluations ${ }^{1}$

\begin{tabular}{|c|c|c|c|c|}
\hline \multirow[b]{2}{*}{ Information } & \multicolumn{4}{|c|}{ Scenario (S) } \\
\hline & S1 & $\mathrm{S} 2$ & S3 & $\mathrm{S} 4$ \\
\hline $\begin{array}{l}\text { Pedigree } \\
\text { Genotypes } \\
\text { Other } \\
\text { Result }\end{array}$ & $\begin{array}{l}P_{S} \\
P_{S} \\
\overline{P_{S}} \text { GEBV }\end{array}$ & $\begin{array}{l}\mathrm{P}_{\mathrm{S}} \\
\mathrm{P}_{\mathrm{S}} \\
\mathrm{GEBV} \mathrm{P}_{\mathrm{L}} \\
\mathrm{P}_{\mathrm{S}}+\mathrm{GEBV}\end{array}$ & $\begin{array}{l}\mathrm{P}_{\mathrm{S}}+\mathrm{P}_{\mathrm{L}} \\
\mathrm{P}_{\mathrm{S}}+\mathrm{P}_{\mathrm{L}} \\
\overline{\mathrm{P}_{\mathrm{S}} \mathrm{P}_{\mathrm{L}} \mathrm{GEBV}}\end{array}$ & $\begin{array}{l}\overline{\mathrm{P}_{\mathrm{S}}} \\
\mathrm{SNP} \mathrm{P}_{\mathrm{L}} \\
\mathrm{P}_{\mathrm{L}-\mathrm{SNP}} \mathrm{GEBV}\end{array}$ \\
\hline
\end{tabular}

evaluation of small populations. Therefore, all information on $\mathrm{P}_{\mathrm{S}}$ plus 221,580 phenotypes, 402,829 pedigree animals, and 53,558 genotypes for $\mathrm{P}_{\mathrm{L}}$ were used in the evaluation; we indicate the output as $\mathrm{P}_{\mathrm{S}} \mathrm{P}_{\mathrm{L}}$ GEBV. The last scenario (S4) assumed that phenotypes, pedigree, and genotypes for $\mathrm{P}_{\mathrm{L}}$ cannot be shared with $\mathrm{P}_{\mathrm{S}}$, but SNP effects can; therefore, GEBV for validation animals from $\mathrm{P}_{\mathrm{S}}$ were calculated by the multiplication of SNP content by SNP effects from $\mathrm{P}_{\mathrm{L}}$. In this scenario, we indicate the output GEBV as $\mathrm{P}_{\mathrm{L}-\mathrm{SNP}}$ GEBV. The average number of records and range for $\mathrm{P}_{S}$ and $\mathrm{P}_{\mathrm{L}}$ are shown in Table 2.

Although it was assumed that $\mathrm{P}_{\mathrm{S}}$ had only 1,000 genotyped animals, we additionally tested 2 situations in which 3,000 or $6,000 \mathrm{P}_{\mathrm{S}}$ animals were genotyped. This was done to investigate the value of adding local instead of external information. The ability to predict true simulated breeding value was assessed in the youngest third of the genotyped animals in the small population. Validation animals had their phenotypes

Table 2. Number of animals with phenotypes, pedigree information, and genotypes (mean of 5 replicates \pm range) for a small population $\left(\mathrm{P}_{\mathrm{S}}\right)$ and a large population $\left(\mathrm{P}_{\mathrm{L}}\right)$

\begin{tabular}{lc}
\hline Source & Mean and range \\
\hline Phenotypes & $3,166 \pm 12$ \\
$\mathrm{P}_{\mathrm{S}}$ & $221,580 \pm 2,318$ \\
$\mathrm{P}_{\mathrm{L}}$ & $22,855 \pm 156$ \\
Pedigree & $402,829 \pm 1,433$ \\
$\mathrm{P}_{\mathrm{S}}$ & \\
$\mathrm{P}_{\mathrm{L}}$ & $1,000 \pm 0$ \\
Genotypes $\mathrm{P}_{\mathrm{S}} 1^{1}$ & $3,000 \pm 0$ \\
$\mathrm{P}_{\mathrm{S}} 3$ & $6,000 \pm 0$ \\
$\mathrm{P}_{\mathrm{S}} 6$ & $53,558 \pm 765$ \\
$\mathrm{P}_{\mathrm{L}}$ & $4,475 \pm 14$ \\
Other & \\
External GEBV $\mathrm{P}_{\mathrm{L}}{ }^{2}$ & \\
\hline
\end{tabular}

\footnotetext{
${ }^{1}$ Three different sets of genotyped animals were tested for the $\mathrm{P}_{\mathrm{S}}$. ${ }^{2}$ GEBV $\mathrm{P}_{\mathrm{L}}=$ genomic EBV from $\mathrm{P}_{\mathrm{L}}$.
}

omitted from evaluations, and correlations between true and estimated breeding values were calculated. All 4 genomic scenarios were compared with a benchmark evaluation where genomic information was not used; therefore, only phenotypes and pedigree for $\mathrm{P}_{\mathrm{S}}$ were used. In addition, Spearman rank correlations between true and estimated BV for the top 100 young animals were calculated when 1,000 and 6,000 genotyped animals from $\mathrm{P}_{\mathrm{S}}$ were used.

\section{Methods of Evaluation}

All analyses were done using software from the BLUPF90 family (Misztal et al., 2015). To verify genetic connection between 2 simulated populations, genetic correlations between animal performances of $\mathrm{P}_{\mathrm{L}}$ and $\mathrm{P}_{\mathrm{S}}$ were estimated. The correlations were estimated with REML approach for each of the 5 replications and then averaged. Genomic EBV were estimated using ssGBLUP (S1 and S3; Aguilar et al., 2010), ssGBLUP with external information (S2; Legarra et al., 2007; Aguilar et al., 2010), and ssGBLUP extended to calculate SNP effects (S4; Wang et al., 2012).

For simplicity and because all data were simulated, the model used for all scenarios accounted for 1 fixed effect (overall mean), a random animal genetic effect, and a random residual.

$$
\mathbf{y}=1 \boldsymbol{\mu}+\mathbf{Z a}+\mathbf{e},
$$

where $\mathbf{y}$ is the vector of phenotypes, $\boldsymbol{\mu}$ is a vector of fixed effect (overall mean), $\mathbf{a}$ is the vector of additive animal effect, $\mathbf{e}$ is the vector of random residual effect, and $\mathbf{Z}$ is the incidence matrix for the random effect in a. It was assumed that $a \sim N\left(0, \mathbf{H} \sigma_{a}^{2}\right)$, in which $\sigma_{a}^{2}$ is the additive genetic variance and $\mathbf{H}$ is the matrix that combines pedigree and genomic relationships. Therefore, in the BLUP mixed model equations, when the inverse of 
the pedigree relationship matrix is replaced by $\mathbf{H}^{-1}$, the model turns into ssGBLUP (Aguilar et al., 2010):

$$
\mathbf{H}^{-1}=\mathbf{A}^{-1}+\left[\begin{array}{cc}
0 & 0 \\
0 & \mathbf{G}^{-1}-\mathbf{A}_{22}^{-1}
\end{array}\right],
$$

where $\mathbf{A}_{22}^{-1}$ is the inverse of a matrix that contains pedigree relationships among genotyped animals, and $\mathbf{G}^{-1}$ is the inverse of the genomic relationship matrix. The $\mathbf{G}$ matrix was created as $0.95 \mathbf{G}^{*}+0.05 \mathbf{A}_{22}$ to avoid singularity problems, and $\mathbf{G}^{*}$ was created as in VanRaden (2008).

For scenario S2, where external information was used, $\mathbf{H}^{-1}$ was adapted from Legarra et al. (2007):

$$
\mathbf{H}^{*-1}=\left[\begin{array}{cc}
\mathbf{H}^{\mathrm{EE}}+\mathbf{T}^{-1}-\mathbf{H}_{\mathrm{EE}}^{-1} & \mathbf{H}^{\mathrm{EI}} \\
\mathbf{H}^{\mathrm{IE}} & \mathbf{H}^{\mathrm{II}}
\end{array}\right],
$$

where $\mathbf{H}^{\mathrm{EE}}, \mathbf{H}^{\mathrm{EI}}, \mathbf{H}^{\mathrm{IE}}, \mathbf{H}^{\mathrm{II}}$ are submatrices of the relationship matrix for external (E) and internal (I) animals, $\mathbf{H}_{\mathrm{EE}}^{-1}$ is the inverse of the relationship matrix among external animals, and $\mathbf{T}$ is a diagonal matrix with prediction error variance for external animals.

In scenario S4, SNP effects were calculated as in Wang et al. (2012) and Aguilar et al. (2014), but with GEBV replaced by the genomic portion of GEBV, which is called direct genomic value (DGV) as in Lourenco et al. (2015):

Step 1: Compute GEBV using ssGBLUP approach and data on only $\mathrm{P}_{\mathrm{L}}$;

Step 2: Compute DGV for each animal i, as $D_{G V}=-\frac{\sum_{j, j \neq i} g^{i j} G_{i} E^{j}}{g^{i i}}$, where $g^{i j}$ is an element of $\mathbf{G}^{-1}$ corresponding to relationships between animal $\mathrm{i}$ and $\mathrm{j}$;

Step 3: Compute SNP effects as $\hat{\mathbf{u}}_{\boldsymbol{k}}=\mathbf{D} \mathbf{Z}^{\prime} \mathbf{G}^{-1}(\mathbf{D G V})$, where $\hat{\mathbf{u}}_{\boldsymbol{k}}$ is the effect of the kth SNP, $\mathbf{D}$ is a diagonal matrix of weights for SNP (we assumed weights equal 1), and $\mathbf{Z}$ is a matrix of centered genotypes for each animal.

\section{RESULTS}

The simulated structure provided strong ties between $\mathrm{P}_{\mathrm{L}}$ and $\mathrm{P}_{\mathrm{S}}$ with genetic correlation between performances for $\mathrm{P}_{\mathrm{L}}$ and for $\mathrm{P}_{\mathrm{S}}$ that averaged $0.84 \pm 0.019$. Accuracies of GEBV for validation animals in $\mathrm{P}_{\mathrm{S}}$ for all scenarios are shown in Figure 1. The validation was primarily done on 334 out of 1,000 genotyped animals, and additionally on 1,000 and 2,000 when the number of genotyped animals was 3,000 and 6,000 , respectively. Accuracy of EBV from the benchmark scenario was 0.31. For scenario S1 that used phenotypes, pedigree, and genotypes only for $\mathrm{P}_{\mathrm{S}}$, a small increase in accuracy was observed (0.32), possibly because of the small number of genotyped animals $(1,000)$. External GEBV for over 4,000 $\mathrm{P}_{\mathrm{L}}$ sires of $\mathrm{P}_{\mathrm{S}}$ animals (S2) did not add significant information for validation animals; in this scenario, accuracy was only 2 points greater than EBV accuracy. When phenotypes, pedigree, and genotypes for $\mathrm{P}_{\mathrm{S}}$ and $\mathrm{P}_{\mathrm{L}}$ were combined for a joint genomic evaluation, a considerable increase of 6 and 5 points in accuracy was observed compared with scenarios $\mathrm{S} 1$ and $\mathrm{S} 2$, respectively. Although scenario S3 could be considered a good option for raising GEBV accuracies in small genotyped populations, accuracy was the greatest when SNP effects derived from $\mathrm{P}_{\mathrm{L}}$ were used to assess GEBV of $\mathrm{P}_{\mathrm{S}}$ validation animals (scenario $\mathrm{S} 4$ ). Accuracy for scenario S4 was, therefore, 0.56, meaning that the difference between scenarios S3 and S4 was 18 points.

When 3,000 and 6,000 genotyped animals were used, the gain in accuracy from scenario S1 compared with the benchmark accuracy of EBV was 6 and 9 points, respectively, and therefore bigger than when only 1,000 animals from $\mathrm{P}_{\mathrm{S}}$ were genotyped (Figure 1), as expected. Small or no benefit was observed in scenario S2; however, a considerable gain of 20 points was observed in scenario S3 compared with S1 when 6,000 animals from $\mathrm{P}_{\mathrm{S}}$ were genotyped (0.62 vs. 0.42). Using SNP effects for $\mathrm{P}_{\mathrm{L}}$ to assess GEBV for validation animals (S4) delivered accuracies that were 7 points greater than in S3 when 3,000 were genotyped, but 4 points lower for 6,000 . Increasing the size of the genotyped local population is valuable, but unrealistic for small populations, and the gain in accuracy may not offset the genotyping cost.

Rank correlations $(\rho)$ between true BV and GEBV for the top 100 young animals were $\rho=0.93$ in $P_{S}$ GEBV and $\mathrm{P}_{\mathrm{S}}+$ GEBV,$\rho=0.95$ in $\mathrm{P}_{\mathrm{S}} \mathrm{P}_{\mathrm{L}}$ GEBV , and $\rho$ $=0.94$ in $\mathrm{P}_{\mathrm{L}-\mathrm{SNP}}$ GEBV evaluations, when the smallest amount of genotyped animals $(1,000)$ was used. In cases where all 6,000 genotyped animals were used, the rank correlations were $\rho=0.96$ in $\mathrm{P}_{\mathrm{S}}$ GEBV and $\mathrm{P}_{\mathrm{S}}+\mathrm{GEBV}$, and $\rho=0.97$ in $\mathrm{P}_{\mathrm{S}} \mathrm{P}_{\mathrm{L}}$ GEBV and $\mathrm{P}_{\mathrm{L}-\mathrm{SNP}}$ GEBV evaluations.

\section{DISCUSSION}

Evaluation accuracy in different genomic prediction scenarios was examined for 2 simulated populations that were genetically linked: a large population (400,000 animals) and a smaller one (6,000 animals). 


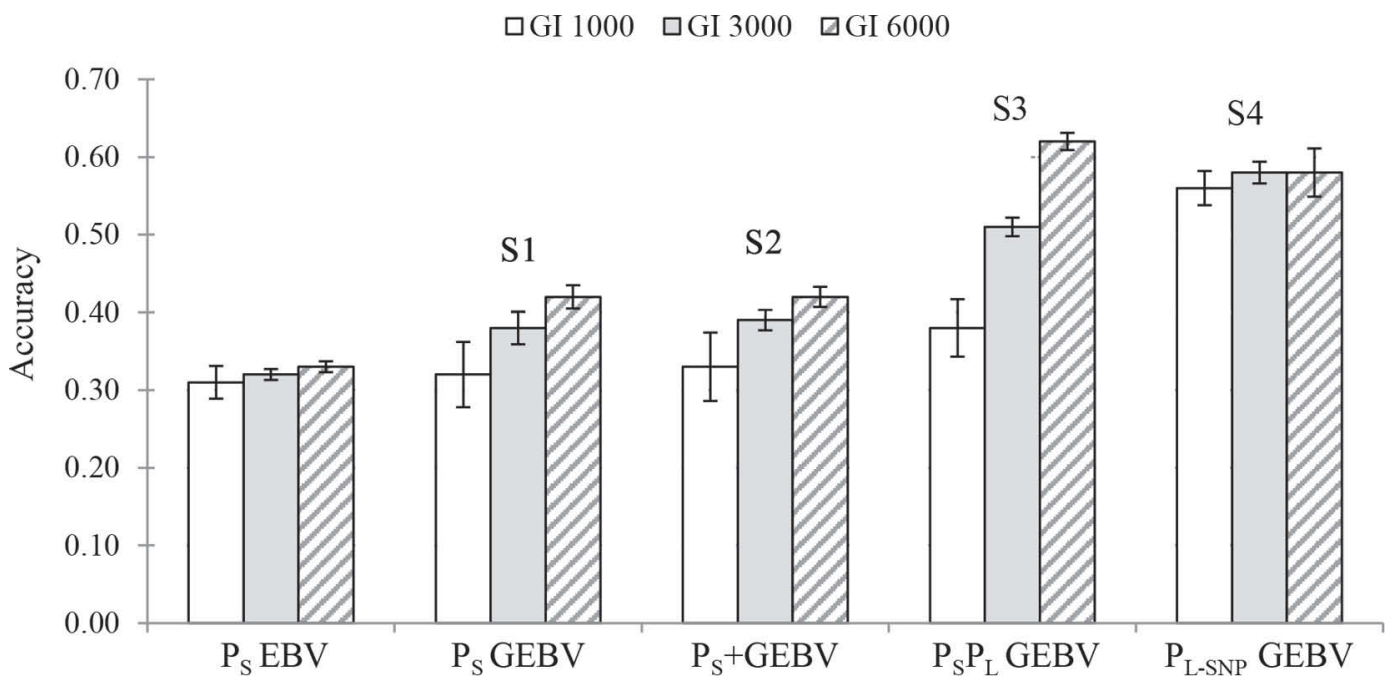

Figure 1. Accuracy of breeding values and SE (based on 5 replicates) for young animals in small population $\left(\mathrm{P}_{\mathrm{S}}\right)$ when genomic information (GI) was included from 1,000 (GI1000), 3,000 (GI3000), or 6,000 (GI6000) $\mathrm{P}_{\mathrm{S}}$ animals. $\mathrm{P}_{\mathrm{S}}$ EBV is EBV obtained with data from $\mathrm{P}_{\mathrm{S}}$; GEBV is genomic EBV obtained only with data from $\mathrm{P}_{\mathrm{S}}$ (scenario S1); $\mathrm{P}_{\mathrm{S}}+$ GEBV is genomic EBV obtained with data from $\mathrm{P}_{\mathrm{S}}$ plus external GEBV from a large population $\left(\mathrm{P}_{\mathrm{L}}\right.$; scenario $\mathrm{S} 2$ ); $\mathrm{P}_{\mathrm{S}} \mathrm{P}_{\mathrm{L}}$ GEBV is genomic EBV obtained with combined data of $\mathrm{P}_{\mathrm{S}}$ and $\mathrm{P}_{\mathrm{L}}$ (scenario S3); $\mathrm{P}_{\mathrm{L}-\mathrm{SNP}}$ GEBV is genomic EBV obtained from SNP effects for $\mathrm{P}_{\mathrm{L}}$ (scenario $\mathrm{S} 4$ ).

In addition, the benefit of including information from a large and well-established population in the evaluation of a smaller population was investigated. Different combinations of phenotypes and genotyped animals were used to calculate GEBV, and different numbers of genotyped animals in the smaller population were additionally tested.

The different scenarios used data generated to mimic a small Holstein population that is tied to a large population that has undergone genomic selection. The genetic correlation between $\mathrm{P}_{\mathrm{S}}$ and $\mathrm{P}_{\mathrm{L}}$ was similar to those used by the Interbull Centre (Uppsala, Sweden) to account for genotype-environment interaction among countries (Jorjani et al., 2005), which suggests that the simulation reflected real well-connected populations. For production traits, Interbull uses genetic correlations as high as 0.85 to 0.98 for well-connected countries with similar managements and environments or as low as 0.75 (Interbull, 2014) in countries with different climates and production systems (e.g., Ireland, Israel, and New Zealand).

When data on $\mathrm{P}_{\mathrm{S}}$ only were used to predict genetic merit, accuracy of EBV without considering genomic information was low $(\sim 0.3)$. Different validation sets (334, 1,000 , or 2,000 animals) produced lower accuracies with higher SE when a smaller number of genotyped animals was used. The decreased accuracies were the result of random sampling of animals from the third generation of $\mathrm{P}_{\mathrm{S}}$, where some of them were poorly connected to the reference population. As expected, high accuracy was reached for scenario S3, which combined phenotypes, pedigree, and genotypes for $\mathrm{P}_{\mathrm{L}}$ and $\mathrm{P}_{\mathrm{S}}$. This scenario also showed the most consistent rank for the top 100 animals compared with true breeding values. Prribyl et al. (2014) reported the highest reliability for breeding values in real Holstein evaluation when records from Interbull and from the local population were combined. Lund et al. (2011) showed that a reference population needs to be large enough to predict GEBV accurately. However, a related population with performance in a modified environment can be treated as a linked subpopulation to increase the reference size. In such a case, the accuracy of GEBV for selection candidates in the small population is highly affected by the level of linkage disequilibrium between markers and QTL as well as by the level of relationships available (Goddard, 2009). Across populations, differences in linkage disequilibrium, allele frequencies, and allele substitution effects of QTL are observed in specific environments (Wientjes et al., 2013). In addition, close family relationships between individuals of different populations often are missing, possibly because of the use of outside sires that originated from different countries.

Some studies have reported large improvement in accuracy when external EBV from a foreign population was used in the evaluation of a local population (Zhang et al., 2002; Vandenplas and Gengler, 2012; Vandenplas et al., 2014). However, the gain in adding external GEBV in our study was minimal. Perhaps increasing daughter groups per sire in $\mathrm{P}_{\mathrm{S}}$ could help to improve 
accuracy, especially if the added genomic information is for external bulls that were strongly used as $\mathrm{P}_{\mathrm{S}}$ sires. As many national breeding programs generally are not part of large consortia (e.g., Interbull and EuroGenomics), additional information on sires and dams is difficult to obtain except for limited genealogical and EBV data. If this is the case, the most relevant approach would be to rely on internal population performance combined with a large number of animals with genomic information and the relationships of all sires used. Using external GEBV of sires could slightly improve the accuracy of prediction for young animals but would also add complexity to the evaluation.

Highly accurate genomic predictions without using pedigree and performance records for $\mathrm{P}_{\mathrm{S}}$ were achieved when SNP effects calculated from $\mathrm{P}_{\mathrm{L}}$ were used to derive GEBV for all sizes of validation population from $\mathrm{P}_{\mathrm{S}}$. In such a case, the constraint is that prediction of GEBV for animals in the small population is limited to only those that have genotypes; however, this may not be an issue if the selection candidates are all genotyped. In the future, genomic information will likely be shared among breeding programs from different countries and this will benefit smaller populations. In addition, higher genetic gain can be expected when a breeding program participates in a consortium and all imported breeding animals are from that consortium. Then GEBV of animals from the breeding program can be calculated by using the large genomic reference population of the consortium, which will force a larger number of local animals to be genotyped. The cost of genotyping can be reduced when all animals with phenotypes and related to the local population are part of the evaluation. In this case, the reliability of evaluations is expected to be higher, helping to offset the genotyping cost. However, because of different environments, checks are necessary to prove that the genetic gain in a small population is evident. If genetic correlation between countries is small, the reliability gain will be reduced. Before the final decision is made, the real population size and structure, production environment, and resources available (e.g., human, technical, and economic) should be considered to determine the best solution for genetic gain in a small dairy population.

Recommendations for the breeding program in the small population genetically linked with a large wellestablished reference population are (1) use SNP effects from the large population or share genotypes with the large population to have GEBV calculated for selection candidates (young animals) and (2) continue the breeding program with genomic information from all genotyped animals included so that predicted GEBV and genetic gain can be verified. Large populations can benefit from shared genomic information from selec- tion candidates in small populations to identify animals with high genetic potential and low inbreeding.

\section{CONCLUSIONS}

Through simulation, prediction accuracy for young animals from a small population was assessed when external information from a genetically linked large population was used. Although the accuracy of genomic selection seems to be limited in small genotyped populations, the inclusion of information on related larger populations is beneficial, suggesting that the implementation of genomic selection may be successful and the genetic progress accelerated in small populations once the information on large populations is made available. In particular, using SNP effects from large related populations can produce genomic predictions that are more accurate than local predictions and almost as accurate as predictions from combined evaluations.

\section{ACKNOWLEDGMENTS}

This study was enabled by Fulbright Scholar Program $68150534-2015 / 16$. We gratefully acknowledge the very helpful comments by the anonymous reviewers.

\section{REFERENCES}

Aguilar, I., I. Misztal, D. L. Johnson, A. Legarra, S. Tsuruta, and T. J. Lawlor. 2010. Hot topic: A unified approach to utilize phenotypic, full pedigree, and genomic information for genetic evaluation of Holstein final score. J. Dairy Sci. 93:743-752. https://doi. org/10.3168/jds.2009-2730.

Aguilar, I., I. Misztal, S. Tsuruta, A. Legarra, and H. Wang. 2014. PREGSF90 - POSTGSF90: Computational tools for the implementation of single-step genomic selection and genome-wide association with ungenotyped individuals in BLUPF90 program. Proc. 10th WCGALP, Vancouver, Canada, 17-22 Aug. 2014. https://www.asas.org/docs/default-source/wcgalp-posters /680_ paper_9756_manuscript_1666_0.pdf?sfvrsn=2.

Council on Dairy Cattle Breeding. 2016. Council on Dairy Cattle Breeding Fee Schedule for Genomic Evaluation Fees. Accessed Aug. 5, 2016. https://www.cdcb.us/News/CDCB\% 20 Fee $\% 20$ Schedule\%20Update\%207-15-2016.pdf.

Cromie, A. R., D. P. Berry, B. Wickham, J. F. Kearney, J. Pena, J. B. C. H. van Kaam, N. Gengler, J. Szyda, U. Schnyder, M. Coffey, B. Moster, K. Hagiya, J. I. Weller, D. Abernethy, and R. Spelman. 2010. International genomic co-operation: Who, what, when, where, why and how? Interbull Bull. 42:72-78.

Goddard, M. E. 2009. Genomic selection: Prediction of accuracy and maximization of long term response. Genetica 136:245-257. https://doi.org/10.1007/s10709-008-9308-0.

Hayes, B. J., P. J. Bowman, A. C. Chamberlain, K. Verbyla, and M. E. Goddard. 2009. Accuracy of genomic breeding values in multibreed dairy cattle populations. Genet. Sel. Evol. 41:51. https:// doi.org/10.1186/1297-9686-41-51.

Interbull. 2014. Interbull routine genetic evaluation for production traits, April 2014. Accessed Mar. 19, 2016. http://www.interbull. org/web/static/mace_evaluations_archive/eval/prod-apr14.html.

Jorjani, H., U. Emanuelson, and W. F. Fikse. 2005. Data subsetting strategies for estimation of across-country genetic correlations. 
J. Dairy Sci. 88:1214-1224. https://doi.org/10.3168/jds.S00220302(05)72788-0.

Legarra, A., J. K. Bertrand, T. Strabel, R. L. Sapp, J. P. Sanchez, and I. Misztal. 2007. Multi-breed genetic evaluation in a Gelbvieh population. J. Anim. Breed. Genet. 124:286-295.

Legarra, A., O. F. Christensen, I. Aguilar, and I. Misztal. 2014. Single Step, a general approach for genomic selection. Livest. Sci. 166:5465. https://doi.org/10.1016/j.livsci.2014.04.029.

Lourenco, D. A. L., S. Tsuruta, B. O. Fragomeni, Y. Masuda, I. Aguilar, A. Legarra, J. K. Bertrand, T. S. Amen, L. Wang, D. W. Moser, and I. Misztal. 2015. Genetic evaluation using single-step genomic best linear unbiased predictor in American Angus. J. Anim. Sci. 93:2653-2662.

Lund, M. S., A. P. W. de Roos, A. G. de Vries, T. Druet, V. Ducrocq, S. Fritz, F. Guillaume, B. Guldbrandtsen, Z. Liu, R. Reents, C. Schrooten, F. Seefried, and G. Su. 2011. A common reference population from four European Holstein populations increases reliability of genomic predictions. Genet. Sel. Evol. 43:43. https://doi. org/10.1186/1297-9686-43-43.

Masuda, Y., I. Misztal, S. Tsuruta, A. Legarra, I. Aguilar, D. A. Lourenco, B. O. Fragomeni, and T. J. Lawlor. 2016. Implementation of genomic recursions in single-step genomic best linear unbiased predictor for US Holsteins with a large number of genotyped animals. J. Dairy Sci. 99:1968-1974. https://doi.org/10.3168/ jds.2015-10540.

Misztal, I., A. Legarra, and I. Aguilar. 2014. Using recursion to compute the inverse of the genomic relationship matrix. J. Dairy Sci. 97:3943-3952. https://doi.org/10.3168/jds.2013-7752.

Misztal, I., S. Tsuruta, D. Lourenco, I. Aguilar, A. Legarra, and Z. Vitezica. 2015. Manual for BLUPF90 family of programs. Accessed Mar. 19, 2016. http://nce.ads.uga.edu/wiki/lib/exe/fetch. php?media=blupf90_all2.pdf.

Patry, G. 2015. EuroGenomics for reliable cattle breeding: How international collaboration fostered an efficient use of the genomics for a reliable cattle breeding. Session: Industry uptake of national (GEBV) and international (GMACE) genomic evaluations. Interbull Industry Meeting, Feb. 25, 2015, Verden, Germany. Accessed Mar. 19, 2016. http://www.interbull.org/static/web/7_2_Patry. pdf

Přibyl, J., J. Bauer, P. Pešek, J. Přibylová, L. Vostrý, and L. Zavadlová. 2014. Domestic and Interbull information in the single step genomic evaluation of Holstein milk production. Czech J. Anim. Sci. 59:409-415.

Sargolzaei, M., and F. S. Schenkel. 2009. QMSIM: A large-scale genome simulator for livestock. Bioinformatics 25:680-681. https:// doi.org/10.1093/bioinformatics/btp045.
Schaeffer, L. R. 1994. Multiple-country comparison of dairy sires. J. Dairy Sci. 77:2671-2678. https://doi.org/10.3168/jds.S00220302(94)77209-X

Schaeffer, L. R. 2006. Strategy for applying genome-wide selection in dairy cattle. J. Anim. Breed. Genet. 123:218-223. https://doi. org/10.1111/j.1439-0388.2006.00595.x.

Vandenplas, J., F. G. Frederic, and N. Gengler. 2014. Unified method to integrate and bled several, potentially related, sources of information for genetic evaluation. Genet. Sel. Evol. 46:59. https://doi. org/10.1186/s12711-014-0059-3.

Vandenplas, J., and N. Gengler. 2012. Comparison and improvements of different Bayesian procedures to integrate external information into genetic evaluations. J. Dairy Sci. 95:1513-1526. https://doi. org/10.3168/jds.2011-4322.

VanRaden, P. M. 2008. Efficient methods to compute genomic predictions. J. Dairy Sci. 91:4414-4423. https://doi.org/10.3168/ jds.2007-0980.

VanRaden, P. M., M. E. Tooker, J. R. Wright, C. Sun, and J. L. Hutchison. 2014. Comparison of single-trait to multi-trait national evaluation for yield, health, and fertility. J. Dairy Sci. 97:79527962. https://doi.org/10.3168/jds.2014-8489.

VanRaden, P. M., C. P. Van Tassell, G. R. Wiggans, T. S. Sonstegard, R. D. Schnabel, J. F. Taylor, and F. S. Schenkel. 2009. Invited review: Reliability of genomic predictions for North American Holstein bulls. J. Dairy Sci. 92:16-24. https://doi.org/10.3168/ jds.2008-1514.

Wang, H., I. Misztal, I. Aguilar, A. Legarra, and W. M. Muir. 2012. Genome-wide association mapping including phenotypes from relatives without genotypes. Genet. Res. (Camb.) 94:73-83. https:// doi.org/10.1017/S0016672312000274

Wientjes, Y. C. J., R. F. Veerkamp, and M. P. L. Calus. 2013. The effect of linkage disequilibrium and family relationships on the reliability of genomic prediction. Genetics 193:621-631. https://doi. org/10.1534/genetics.112.146290.

Wiggans, G. R., P. M. VanRaden, and T. A. Cooper. 2011. The genomic evaluation system in the United States: Past, present, future. J. Dairy Sci. 94:3202-3211. https://doi.org/10.3168/jds.2010-3866.

Zhang, Z. W., R. L. Quaas, and E. J. Pollak. 2002. Simulation study on the effects of incorporating external genetic evaluation results. Commun. 20-14 in Proc. 7th World Congr. Genet. Applied Livest. Prod., Montpellier, France. INRA, Castanet-Tolosan, Cedex, France. 